\title{
Energy expenditure in disease: time to revisit?
}

\author{
Eileen R. Gibney \\ Darwin College, Silver Street, Cambridge CB3 9EU, UK and \\ Human Nutrition Unit, Rowett Research Institute, Greenburn Road, Bucksburn, Aberdeen AB21 9SB, UK
}

\begin{abstract}
Knowledge of energy expenditure is especially important in disease, and may in fact help in the understanding of the pathophysiology of wasting associated with disease. Energy requirements in a clinical setting are often 'prescribed' by health professionals, either directly through enteral or parenteral feeding, or perhaps controlled through a hospital diet. Studies initially suggested an increase in energy expenditure, and thus energy requirements, as a direct result of an increase in basal metabolic rate often seen in disease. However, many problems exist in the measurement of BMR in a disease situation, due to the effects of drugs, clinical practice, feeding or possibly anxiety either as a cause of the disease or the measurement itself. These problems could in themselves contribute to the rise in metabolism seen in disease. More recently, however, with the use of tracer techniques such as doubly-labelled water and the bicarbonate-urea method, more accurate estimates of energy expenditure, and thus energy requirements, have been made. Some such measurements have in fact shown that even with an elevated BMR, free-living total energy expenditure can in fact be reduced in many disease situations, suggesting a reduced rather than an increased energy requirement. The present review investigates measurements of total energy expenditure in disease to explore the hypothesis that energy expenditure in disease, even with an elevated BMR, can in fact be reduced due to a concurrent reduction in physical activity.
\end{abstract}

Energy expenditure: Resting metabolic rate: Disease: Energy requirements

Measurement of energy expenditure (EE) in both healthy individuals and different groups of patients is fundamental in the establishment of accurate estimates of energy requirements in both health and disease, and also provides an insight into the mechanism of the wasting process associated with disease (Nelson et al. 1994; Elia, 1995). Such information is clinically useful for the prescription of energy and protein nutrition, both of which aim to avoid the detrimental effects of overfeeding and underfeeding (Long et al. 1979; McClave et al. 1998).

Total EE (TEE) in its simplest form is comprised of three components, the sum of which determines the energy requirement for any individual:

1. BMR;

2. thermogenesis, usually dietary-induced thermogenesis (DIT);

3. physical activity (PA).

Previously, energy requirements in disease had been thought to be elevated due to a measured increase in BMR often observed with disease. Estimates of EE and energy intake provided by different health organizations (Department of Health, 1991) are usually given as a multiple of BMR, either measured using indirect calorimetry or estimated using standard equations (Schofield et al. 1985). However, prediction of TEE from BMR is liable to errors, particularly when BMR is elevated. The use of tracer techniques have shown that even when BMR is increased TEE can actually be reduced (Goran et al. 1994; Gibney et al. 1996) due to a concurrent reduction in PA (Fig. 1). Since the energy cost of PA is the most variable component of TEE, and is affected in many different ways by various diseases, TEE in clinical practice can be very variable.

\section{Interpretation of measurements of BMR}

An individual's true BMR can only be accurately measured under the strict conditions indicated in Table 1. Such conditions can be difficult to meet with patients in a clinical setting. The effects of continuous or intermittent feeding, drug administration and the stress of trauma are difficult to 


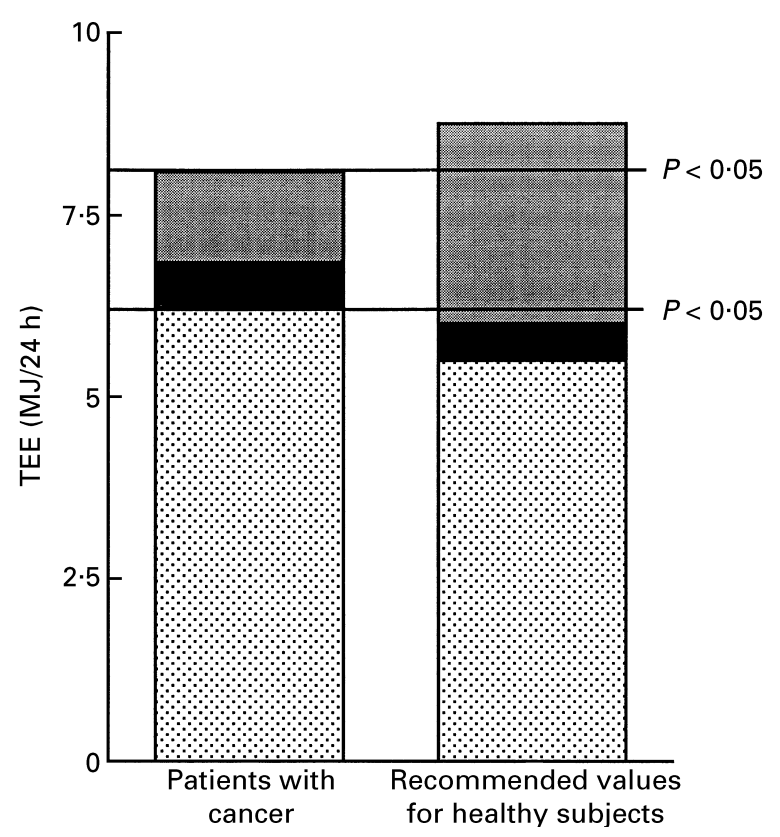

Fig. 1. Total energy expenditure (TEE) in patients with lung cancer (Gibney et al. 1996) compared with recommended values

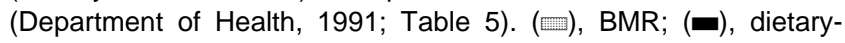

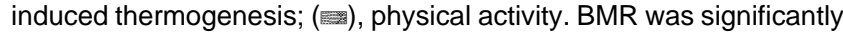
increased $(P<0.05)$ and TEE significantly reduced $(P<0.05)$ in patients with lung cancer compared with recommended values for healthy subjects.

control, although they are known to influence BMR. As true measurements of BMR may be difficult to obtain, an alternative, i.e. resting metabolic rate (RMR), can be measured more easily, e.g. in the fed state, after drug administration or blood transfusion. It is important to note however that BMR and RMR differ by about 10-15\% (Garrow \& James, 1993).

In disease BMR can deviate from normal for a number of reasons (Table 2), many of which are difficult to avoid. Berke et al. (1992) showed that even pretesting conditions had an effect on subsequent measurements of metabolic rate. They demonstrated that when measurements of RMR were taken under 'out patient' conditions (i.e. when individuals made their way to the test centre on the morning of the measurement), measurements of RMR were overestimated by an average of $8 \%$.

It is well known that ingestion of food can cause an increase in basal metabolism (Romon et al. 1993; Reed \& Hill, 1996). The term 'DIT' encompasses the full physical response to the ingestion of food (Garrow \& James, 1993). DIT is typically assumed to correspond to approximately $10 \%$ of the energy content of a normal meal or $10 \%$ of TEE in a weight-stable individual. Often, in clinical situations patients are maintained on strict dietary regimens, including parenteral or enteral feeding $(24 \mathrm{~h}$, overnight and bolus regimens). Measurements taken without proper interruption of feeding for an appropriate length of time will give a misleadingly high estimation of BMR which could be misinterpreted as being due to the hypermetabolism of disease.
Table 1. Standardized conditions for measurement of BMR Postprandial state, $12-14 \mathrm{~h}$ after eating Completely relaxed and still, usually shortly after waking Thermoneutral environment Free from the thermic effect of drugs 20-30 min of stable measurements

Table 2. Problems associated with measurements of BMR in disease

Variations in BMR, both with respect to time of day and course of disease (ebb and flow phases)

Effect of pretest conditions on subsequent measurements

Unknown and/or unreported regimen of drugs

Unknown and/or unreported feeding regimen

Blood transfusion

Anxiety due to measurement

Spastic disorders

Drugs can produce either an increase or a decrease in BMR and/or PA (Demark-Wahnefried et al. 1997; Diffey et al. 1997). Dempsey et al. (1985) investigated the effect of sedative dosage on EE in critically-ill ventilated patients. They found that as the dosage of sedative increased, EE decreased, with some individuals reaching only $60 \%$ of predicted EE on the high doses of sedative. The same conclusion was drawn by Fried et al. (1989), who also showed a significant $(P<0.05)$ decrease in measured EE in their sedated group.

It is a well documented fact that BMR, even in healthy individuals, can vary throughout the course of the day (Cunningham, 1980; Soares \& Shetty, 1986). It is also important to note that BMR can vary not only during the day, but also considerably from day-to-day, especially in the early phases of infectious disease and trauma. Cuthbertson's (1942) classic work during the 1940s described the ebb and flow phases of injury, and the associated changes in $\mathrm{O}_{2}$ consumption. He noted that after an initial decrease in $\mathrm{O}_{2}$ consumption (ebb phase) individuals showed a marked increase in $\mathrm{O}_{2}$ consumption (flow phase) which slowly returned to normal. More recently, Young et al. (1985) assessed repeated measurements of BMR in hospitalized patients suffering from severe trauma. Measurements of metabolic rate were initially found to be 1.5 times that of predicted BMR, only returning to approximately normal levels at $22 \mathrm{~d}$ after the initial trauma.

If recommendations for energy requirements are to be based on measurements of BMR, then when should the measurements be made? If a measurement is taken at the peak of metabolism, and recommendations of energy intake are based on this measurement, then for the majority of the duration of the trauma, an individual will receive an energy intake that is in excess of requirements. Conversely, if a measurement is taken at a point of reduced metabolism, then an individual may become more malnourished during the course of the illness. What must be stressed is the need to estimate the provision of energy requirements over a period of time. In essence, what we really need to know is the 
pattern of BMR in any given disease, and so should not base recommendations on single estimates of BMR, since recommendations based on single estimates of BMR are more likely to be in error.

\section{Measurements of total energy expenditure}

TEE can be measured using a number of different methods (for review, see Murgatroyd et al. 1993):

1. $24 \mathrm{~h}$ respiratory gas exchange (indirect calorimetry);

2. doubly-labelled water;

3. bicarbonate-urea method;

4. heart-rate monitoring.

\section{Indirect calorimetry}

Indirect calorimeters measure $\mathrm{CO}_{2}$ production and $\mathrm{O}_{2}$ consumption, which are used in the calculation of EE, in the context of TEE. To make full estimates of TEE using indirect calorimetry, subjects must be confined to a wholebody chamber to ensure a complete $24 \mathrm{~h}$ measurement. Measurements in such chambers give important information about EE under controlled conditions, but do not necessarily reproduce conditions in free-living circumstances. One circumstance in clinical practice, i.e. continuous ventilation in critically-ill patients, allows the measurement of $24 \mathrm{~h}$ TEE outside a respiratory chamber; details of such studies will be discussed later (p. 202).

\section{Doubly-labelled water method}

The doubly-labelled water method allows measurement of free-living TEE through oral administration of stable isotopes of water, ${ }^{2} \mathrm{H}_{2} \mathrm{O}$ and $\mathrm{H}_{2}{ }^{18} \mathrm{O}$ (Lifson \& McClintock, 1956; Coward, 1988). The technique is based on the principle that after mixing with total body water, the ${ }^{2} \mathrm{H}$ is lost from the body only as water and the ${ }^{18} \mathrm{O}$ is lost both as water and $\mathrm{CO}_{2}$. Thus, the difference in the rates of loss of isotopes from the body is due to $\mathrm{CO}_{2}$ production, from which an estimate of TEE can be made. The disappearance from the body is typically measured over two half-lives of the isotope, about $12-14 \mathrm{~d}$ in adults. Although the method is non-invasive and widely used, it only gives an average daily estimate of TEE over the $14 \mathrm{~d}$ period and is unable to assess day-to-day variation. Validation studies against whole-body indirect calorimetry have shown the method to be accurate to within a mean (SD $10 \%$ ) (Ravussin et al. 1991; Klein et al. 1984; Schoeller et al. 1986; Schoeller \& Webb, 1984; Westerterp et al. 1988; Parkinson, 1990).

\section{Bicarbonate-urea method}

The bicarbonate-urea method is a relatively novel method for measuring TEE in free-living human subjects. Like the doubly-labelled water technique it is essentially an isotopicdilution technique, measuring endogenous $\mathrm{CO}_{2}$ production. Labelled $\mathrm{CO}_{2}$, given subcutaneously as $\mathrm{H}^{14} \mathrm{CO}_{3}^{-}$, is diluted by the $\mathrm{CO}_{2}$ produced in the body. The extent of this dilution, measured through the specific activity of urinary urea, allows the calculation of $\mathrm{CO}_{2}$ production in the body. Using an appropriate value for the energy equivalent of $\mathrm{CO}_{2}$ (Elia, 1991), EE can then be estimated. Unlike the doubly-labelled water technique, the bicarbonate-urea method can make measurements over periods of $24 \mathrm{~h}$, allowing the study of day-to-day variation in free-living conditions. Such day-today measurements may be important in a clinical setting as EE may vary from day-to-day during the course of a disease or trauma. This method has been validated in both healthy individuals (Elia et al. 1995) and those with disease (Gibney et al. 1997b; E Gibney, J Jennings, SA Jebb, PR Murgatroyd, A Wright and M Elia, unpublished results).

\section{Heart-rate monitoring}

Heart-rate monitoring is a simple and inexpensive method of measuring free-living TEE. There are a number of different heart-rate monitoring and recording devices that allow minute-to-minute recording of a heart rate over a set period of time. By measuring heart rate at different levels of PA and creating individual calibration curves, an estimation of EE can be made from such recordings of heart rate. This method has been extensively validated against a number of different methods (e.g. doubly-labelled water and indirect calorimetry) in both adults and children (Dauncey \& James, 1979; Spurr et al. 1988; Ceesay et al. 1989). This method is not typically used in a disease population, as the physical limitations of the population group that inhibit the ability to obtain a proper calibration curve (bedridden, fatigue and injuries), and also the multiple clinical factors that affect heart rate.

\section{Interpretation of measurements of total energy expenditure}

The second part of the present review investigates the hypothesis, that, although an elevated BMR is seen in many disease situations, the increase in BMR is counteracted or more than counteracted by a decrease in PA. This hypothesis was examined by comparing results obtained in studies measuring energy expenditure in disease with values obtained in healthy individuals. The theory that energy requirements may in fact be reduced is in contrast with the physical wasting seen in disease, which may be due to a number of reasons, including negative energy balance (Hellerstein et al. 1990; Elia, 1995), immobility (Deitrick et al. 1948) or high protein requirements compared with a standard diet (Long et al. 1979). The present paper, however, will only attempt to discuss the overall energy requirements, and does not investigate the macronutrient composition of any given diet.

\section{Methods}

All studies measuring free-living TEE in different inflammatory disease states were examined. These studies included those using the doubly-labelled water method, bicarbonate-urea method, heart-rate monitoring and indirect calorimetry. Studies that did not contain a true $24 \mathrm{~h}$ measurement of TEE and used only partial measurements as an estimate were excluded. Studies of stable congenital 
disease conditions (heart defects, ventricular septal defects, etc.) were also excluded.

The following information was obtained from the literature review: age; weight; height; BMI; sample size; method of measurement of EE; duration of study; location of study; measured BMR; predicted BMR; TEE. Results from individual patients were included whenever possible, otherwise the group mean data was used. To allow for different comparisons, results were expressed in a number of different ways: TEE per kg; PA level; predicted PA level (Schofield et al. 1985); energy expended in PA plus thermogenesis (PA + DIT); energy expended in PA + DIT per kg; energy expended in PA; energy expended in PA per $\mathrm{kg}$; disease factor.

In studies where indirect calorimetry was carried out during feeding (resting EE) it was assumed that DIT was $10 \%$ of the TEE. In studies where BMR was actually measured DIT was again assumed to be $10 \%$ of the EE. The energy cost of PA was calculated as being equal to TEE BMR - DIT. This calculation does not take into account thermogenesis due to other causes (e.g. drugs, coldness), but the value probably gives a good approximation of PA.

The data of Black et al. (1996) for measurements of EE, obtained using doubly-labelled water, were used to compare the results of TEE in disease with those of healthy individuals. Dietary reference values (Department of Health, 1991) were used for comparison with recommended intakes for healthy individuals. The studies were separated into two categories: those carried out in hospital; those carried out at home. Mean values for each study are given in Tables 3 and 4 with values for healthy individuals and recommended reference values shown in Table 5.

\section{Results}

As hypothesized, many studies demonstrated a reduced TEE in comparison with reference values for healthy individuals. This reduction was evident in the study of Gibney et al. (1996) in patients with small-cell lung cancer (Fig. 1). Whole-body indirect calorimetry indicated that values for BMR were significantly $(P<0.05)$ elevated in the lungcancer group by a mean of $6 \%$ when compared with predicted values (Schofield et al. 1985). These results are close to those found in a similar but larger group of patients (Jebb et al. 1994). It is important to note, however, that TEE, measured under free-living conditions using the bicarbonate-urea technique in patients with lung cancer, was significantly reduced $(8.9 \mathrm{MJ} / \mathrm{d})$ compared with reference control values $(9.6 \mathrm{MJ} / \mathrm{d})$. Furthermore, PA accounted for $21 \%$ of the TEE in the patients with cancer compared with $31 \%$ in reference controls (Department of Health, $1991 ; P<0 \cdot 05)$. Such results apply to a variety of clinical conditions, demonstrated by the fact that TEE per $\mathrm{kg}$ was reduced in the majority of studies when compared with age-matched controls (see Table 5). Studies were conducted both in hospital (Table 4) and at home (Table 3).

Measurement of EE in critically-ill patients is, as mentioned previously, of particular importance as energy intake is controlled by the clinician either through parenteral or enteral feeding (Weissman et al. 1986; Bruder et al. 1994). Weekes \& Elia (1996) measured 24 h EE by indirect calorimetry in critically-ill head-injured patients whilst they were being maintained on continuous ventilation. This study highlighted several interesting points. First, as there was very little voluntary movement in these individuals, EE was stable throughout the day, thus the measurement of TEE was similar if not equal to any measurement of RMR. This value was $35 \%$ above BMR of study controls of the same age, weight and height, but irrespective of whether measurements of TEE were expressed in absolute terms, in relation to body weight or as multiples of BMR, TEE was reduced in this group. The results mirror those obtained by Pullicino (1991) in a similar cohort of patients. Second, Weekes \& Elia (1996) demonstrated that EE decreased significantly $(P<0.05)$ as time progressed, returning to normal a full $12-19 \mathrm{~d}$ after initial injury.

Patients with burns are well known to be hypermetabolic as a result of the 'injury response' (heat loss across the damaged skin; Long et al. 1979; Goran et al. 1991). Royall et al. (1994) measured EE in a group of twenty adults with severe burns (severe burn area $>30 \%$ ) whilst being maintained on continuous ventilation. Although RMR was $37 \%$ higher than that in controls, PA was virtually nonexistent, which more than compensated for this substantial increase in RMR. This finding would then suggest that the energy requirement in this particular group should perhaps be reduced, even though an extremely high metabolic rate was recorded. Several formulas have been used to estimate energy requirements in these patients (Long, 1979; Wolfe, 1982; Cunningham et al. 1989; Goran et al. 1991), with some equations prescribing up to $200 \%$ of predicted BMR (Mildreth \& Carvajal, 1982; Guzman et al. 1994). In their study of stable patients with a severe burn area of $37 \%$, Royall et al. (1994) recommended that an activity factor of $20 \%$ should be added to the measured resting EE to account for daily requirements. However, caution should be used in generally accepting this recommendation because of the considerable variability and changes over time in patients.

Human immunodeficiency virus (HIV) is responsible for the acquired immunodeficiency syndrome (AIDS). AIDS is in itself diagnosed using criteria advocated by the Centers for Disease Control, Center for Infectious Diseases (1987) classification as a greater than $10 \%$ weight loss together with more than $30 \mathrm{~d}$ of constitutional symptoms in individuals with HIV (Hellerstein et al. 1990). Thus, measurement and understanding of such wasting associated with AIDS is of considerable importance. Schwenk et al. (1996) reviewed measurements of RMR in HIV patients, and concluded that it is unlikely that hypermetabolism by itself is the major cause of weight loss in HIV-infected patients. They suggested that weight loss is seen only in combination with another disorder such as anorexia or malabsorption. These thoughts were mirrored by Hellerstein et al. (1990), who suggested that malnutrition is not only a result of the HIV infection, but may also be a contributing cofactor to the onset of AIDS, due to the reduced cellular immunity seen with malnutrition. Two studies discussed in the present review which measured free-living TEE in HIV patients (Paton et al. 1996; Heijligenberg et al. 1997) reported an increase in RMR (a mean increase of $10 \%$ in the study by Heijligenberg et al. 1997), but no difference in 


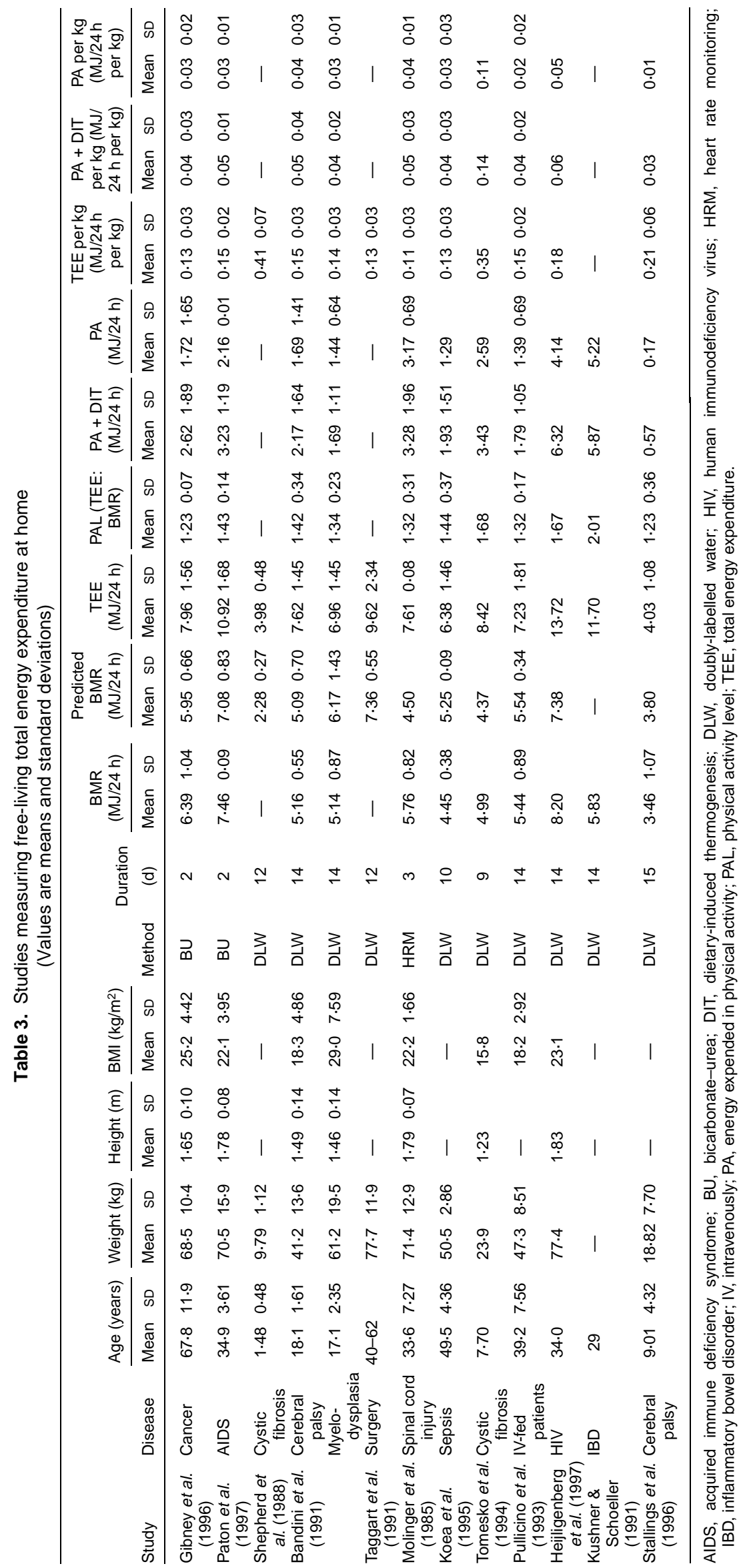




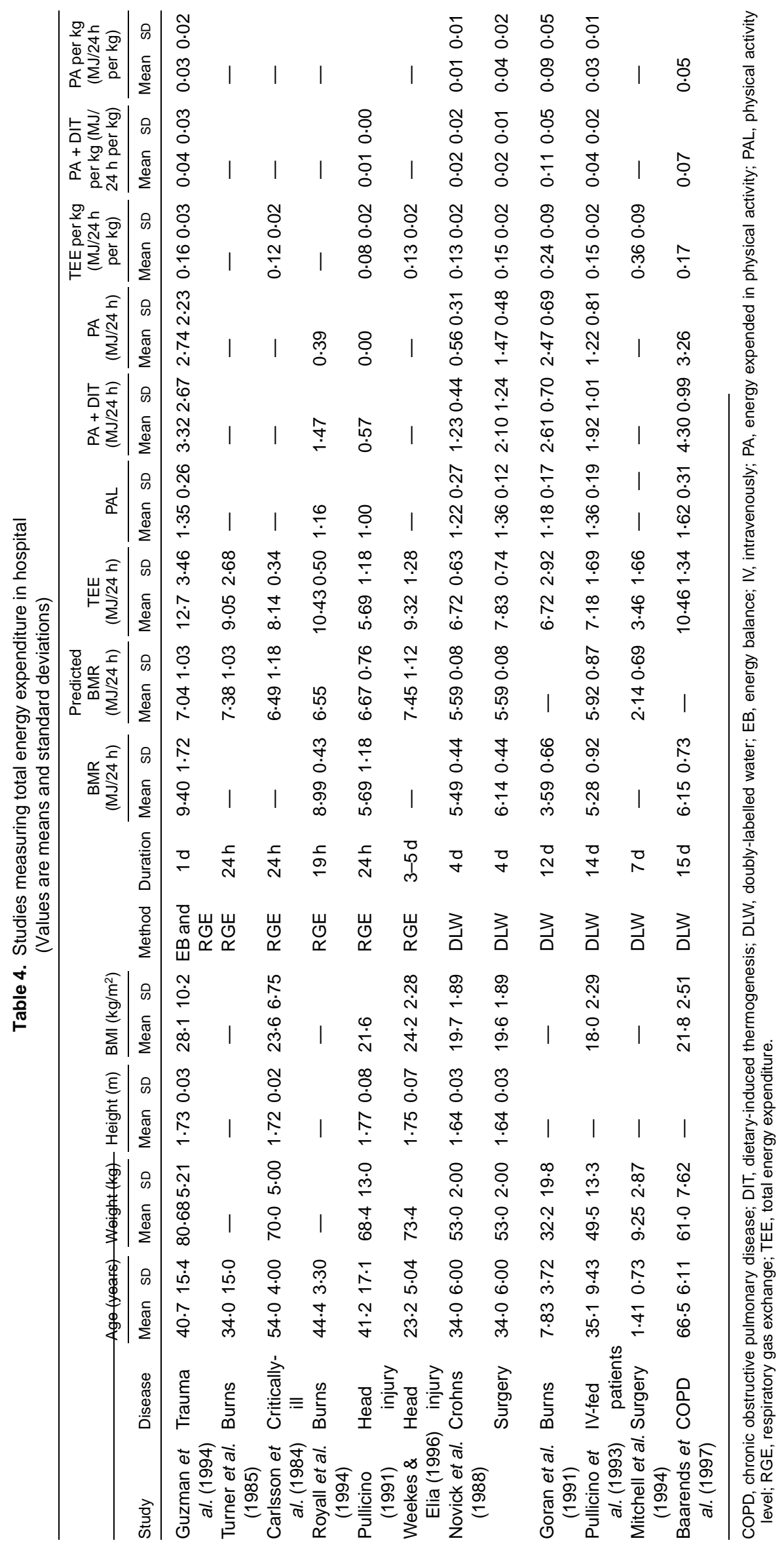


Table 5. Reference values for energy expenditure of healthy subjects (Black et al. 1996) and recommended reference values (Department of Health, 1991)

\begin{tabular}{|c|c|c|c|c|c|c|c|c|c|c|c|}
\hline Reference & & $\begin{array}{c}\text { Age } \\
\text { (years) }\end{array}$ & $\begin{array}{c}\text { Weight } \\
(\mathrm{kg})\end{array}$ & $\begin{array}{c}\text { TEE } \\
(\mathrm{MJ} / \mathrm{d})\end{array}$ & $\begin{array}{c}\text { BMR } \\
(\mathrm{MJ} / \mathrm{d})\end{array}$ & $\begin{array}{c}\text { RMR } \\
(\mathrm{MJ} / \mathrm{d})\end{array}$ & $\begin{array}{c}P A+D I T \\
(M J / d)\end{array}$ & $\begin{array}{c}\text { PA } \\
(\mathrm{MJ} / \mathrm{d})\end{array}$ & $\begin{array}{c}\text { TEE per kg } \\
(\mathrm{MJ} / \mathrm{kg} \text { per } \mathrm{d})\end{array}$ & $\begin{array}{c}\mathrm{PA} / \mathrm{kg} \\
(\mathrm{MJ} / \mathrm{kg} \text { per d) }\end{array}$ & $\begin{array}{l}\text { PA + DIT per kg } \\
(\mathrm{MJ} / \mathrm{kg} \text { per } \mathrm{d})\end{array}$ \\
\hline \multirow{14}{*}{$\begin{array}{l}\text { Black et } \\
\text { al.(1996) }\end{array}$} & \multirow[t]{7}{*}{ Males } & 3.50 & $19 \cdot 7$ & $6 \cdot 10$ & 3.80 & 4.41 & $22 \cdot 2$ & 1.69 & 0.31 & 0.09 & 0.11 \\
\hline & & $9 \cdot 50$ & $40 \cdot 7$ & $9 \cdot 80$ & $5 \cdot 70$ & $6 \cdot 68$ & $24 \cdot 1$ & $3 \cdot 12$ & 0.24 & 0.08 & 0.10 \\
\hline & & $15 \cdot 0$ & $72 \cdot 0$ & $14 \cdot 1$ & $8 \cdot 10$ & $9 \cdot 51$ & $46 \cdot 0$ & 4.59 & 0.19 & 0.06 & 0.08 \\
\hline & & 23.5 & $75 \cdot 6$ & $13 \cdot 8$ & $7 \cdot 50$ & $8 \cdot 88$ & $6 \cdot 30$ & 4.92 & 0.18 & 0.07 & 0.07 \\
\hline & & 34.5 & $86 \cdot 1$ & $14 \cdot 3$ & $8 \cdot 20$ & $9 \cdot 63$ & $6 \cdot 10$ & $4 \cdot 67$ & 0.17 & 0.05 & 0.06 \\
\hline & & $52 \cdot 0$ & $77 \cdot 0$ & 11.5 & $7 \cdot 00$ & $8 \cdot 15$ & 4.50 & $3 \cdot 35$ & 0.15 & 0.04 & 0.05 \\
\hline & & $75 \cdot 0$ & $72 \cdot 6$ & $9 \cdot 20$ & $6 \cdot 00$ & 6.92 & $3 \cdot 20$ & $2 \cdot 28$ & 0.13 & 0.03 & $0 \cdot 10$ \\
\hline & \multirow[t]{7}{*}{ Females } & 3.50 & $18 \cdot 4$ & $5 \cdot 50$ & $3 \cdot 60$ & $4 \cdot 15$ & 1.90 & $1 \cdot 35$ & 0.29 & 0.07 & 0.08 \\
\hline & & $9 \cdot 50$ & $33 \cdot 3$ & 8.00 & $4 \cdot 80$ & $5 \cdot 60$ & $3 \cdot 20$ & $2 \cdot 40$ & 0.24 & 0.07 & 0.09 \\
\hline & & $15 \cdot 0$ & 71.5 & 11.4 & $6 \cdot 70$ & $7 \cdot 84$ & $4 \cdot 70$ & 3.56 & 0.16 & 0.05 & 0.07 \\
\hline & & 23.5 & $69 \cdot 2$ & $10 \cdot 4$ & $6 \cdot 20$ & $7 \cdot 24$ & $4 \cdot 20$ & $3 \cdot 16$ & $0 \cdot 15$ & 0.05 & 0.06 \\
\hline & & 34.5 & 67.9 & $10 \cdot 0$ & $6 \cdot 00$ & $7 \cdot 00$ & $4 \cdot 10$ & 3.00 & 0.15 & 0.04 & 0.06 \\
\hline & & $52 \cdot 0$ & $70 \cdot 0$ & $9 \cdot 80$ & $5 \cdot 80$ & $6 \cdot 78$ & 4.00 & 3.02 & 0.14 & 0.04 & 0.06 \\
\hline & & $75 \cdot 0$ & $48 \cdot 3$ & $6 \cdot 10$ & $4 \cdot 10$ & $4 \cdot 71$ & 1.90 & $1 \cdot 39$ & $0 \cdot 13$ & 0.03 & 0.04 \\
\hline \multirow{18}{*}{$\begin{array}{l}\text { Department } \\
\text { of Health } \\
(1991)\end{array}$} & \multirow[t]{10}{*}{ Males } & $2 \cdot 00$ & 12.4 & $5 \cdot 15$ & 2.96 & 3.48 & $2 \cdot 19$ & 1.67 & 0.42 & 0.14 & 0.18 \\
\hline & & 5.00 & $19 \cdot 3$ & $7 \cdot 16$ & 3.94 & $4 \cdot 66$ & $3 \cdot 22$ & 2.50 & 0.37 & 0.13 & 0.17 \\
\hline & & $8 \cdot 50$ & $28 \cdot 3$ & $8 \cdot 24$ & $4 \cdot 79$ & $5 \cdot 61$ & $3 \cdot 45$ & $2 \cdot 63$ & 0.29 & 0.09 & $0 \cdot 12$ \\
\hline & & $12 \cdot 5$ & 40.5 & $9 \cdot 27$ & 5.94 & $6 \cdot 87$ & $3 \cdot 33$ & $2 \cdot 40$ & 0.14 & 0.06 & 0.08 \\
\hline & & $16 \cdot 5$ & 62.5 & 11.5 & 6.94 & 8.09 & 4.57 & $3 \cdot 42$ & 0.13 & 0.05 & 0.07 \\
\hline & & 34.0 & $74 \cdot 0$ & 11.5 & $7 \cdot 21$ & $8 \cdot 36$ & $4 \cdot 32$ & $3 \cdot 17$ & 0.16 & 0.04 & 0.06 \\
\hline & & 54.5 & $74 \cdot 0$ & 11.5 & $7 \cdot 21$ & $8 \cdot 36$ & $4 \cdot 32$ & $3 \cdot 17$ & 0.16 & 0.04 & 0.06 \\
\hline & & 62.0 & $74 \cdot 0$ & 9.93 & $7 \cdot 21$ & $8 \cdot 36$ & $4 \cdot 32$ & $3 \cdot 17$ & $0 \cdot 16$ & 0.04 & 0.06 \\
\hline & & 69.5 & $71 \cdot 0$ & $9 \cdot 50$ & 5.94 & $6 \cdot 89$ & 3.56 & $2 \cdot 61$ & 0.14 & 0.04 & 0.05 \\
\hline & & $75 \cdot 0$ & $69 \cdot 0$ & $9 \cdot 34$ & $5 \cdot 84$ & $6 \cdot 77$ & 3.50 & 2.57 & 0.13 & 0.03 & 0.05 \\
\hline & \multirow[t]{8}{*}{ Females } & $2 \cdot 00$ & $11 \cdot 8$ & $4 \cdot 86$ & $2 \cdot 75$ & $3 \cdot 24$ & $2 \cdot 11$ & 1.62 & 0.41 & 0.14 & $0 \cdot 18$ \\
\hline & & $5 \cdot 00$ & 18.9 & $6 \cdot 46$ & $3 \cdot 64$ & $4 \cdot 29$ & $2 \cdot 82$ & $2 \cdot 17$ & 0.34 & $0 \cdot 12$ & $0 \cdot 15$ \\
\hline & & $8 \cdot 50$ & $28 \cdot 2$ & $7 \cdot 28$ & 4.43 & $5 \cdot 21$ & $2 \cdot 85$ & $2 \cdot 07$ & 0.26 & 0.08 & $0 \cdot 10$ \\
\hline & & $34 \cdot 0$ & $60 \cdot 0$ & 8.93 & 5.58 & $6 \cdot 47$ & $3 \cdot 35$ & $2 \cdot 46$ & 0.15 & 0.04 & 0.06 \\
\hline & & 54.5 & $63 \cdot 0$ & 9.09 & $5 \cdot 68$ & 6.59 & $3 \cdot 41$ & $2 \cdot 50$ & 0.14 & 0.04 & 0.05 \\
\hline & & $62 \cdot 0$ & 63.5 & $9 \cdot 10$ & $5 \cdot 69$ & $6 \cdot 60$ & $3 \cdot 14$ & $2 \cdot 50$ & 0.14 & 0.04 & 0.05 \\
\hline & & 69.5 & 63.0 & $8 \cdot 24$ & $5 \cdot 15$ & 5.97 & 3.09 & $2 \cdot 27$ & 0.14 & 0.04 & 0.05 \\
\hline & & $75 \cdot 0$ & $60 \cdot 0$ & 8.06 & 5.04 & $5 \cdot 85$ & 3.02 & $2 \cdot 24$ & 0.13 & 0.04 & 0.05 \\
\hline
\end{tabular}

DIT, dietary-induced thermogenesis; PA, physical activity; RMR, resting metabolic rate; TEE, total energy expenditure.

TEE when compared with reference controls. These observations are consistent with a concurrent reduction in PA (Table 3). Such results do not help to explain the characteristic weight loss seen in this disease, and would suggest that the answer may be a combination of disorders, as previously suggested (Hellerstein et al. 1990).

\section{Conclusions}

The present paper confirms that EE is very variable in disease (Tables 3 and 4; Goran et al. 1985; Elia, 1995). Such variations are partly due to variable effects of disease on BMR and PA, the presence of variable nutritional status (undernutrition tends to reduce predicted BMR) and inconsistent or inappropriate procedures for measuring and interpreting measurements of EE. What became evident in researching this topic is the lack of reporting of any such deviations, i.e. measurements being made whilst feeding, or under an unknown or unreported influence of drugs. Reporting such deviations and also reporting the timing of the measurement with respect to the trauma or disease stage would allow other observers to fully evaluate the results obtained, and allow proper comparisons from group-togroup. General recommendations are given in Table 6 .

The appropriate use of tracer techniques and indirect calorimetry in a wider range of disease states would allow a greater understanding of the pathophysiology of wasting, and at the same time provide a better basis for recommendations as to the energy requirement in disease. It is important to affirm that measurements of EE in disease will only allow the clinician to assess the energy requirement of an individual with respect to the initial body composition of the 
Table 6. Recommendations for the reporting of assessments of energy requirements in disease

Ensure most, if not all, conditions of BMR measurements are fulfilled Report any deviations from strict conditions of BMR

Report time of measurement, both with respect to time of day and course of the disease

Document drug and feeding regimens regardless of whether measurement is taken free from thermic effects Take note of initial body composition of individual

patient involved. Additional energy intake may be required for tissue repletion, especially during recovery from illness, and in individuals who are initially malnourished. Although the requirements of different patients vary widely, the principles of nutritional care remain very similar.

\section{References}

Baarends EM, Schols AMWJ, Pannemans DLE, Westerterp KR \& Wouters EFM (1997) Total free living energy expenditure in patients with severe chronic obstructive pulmonary disease. American Journal of Respiratory Critical Care Medicine 155, $549-554$.

Bandini LG, Schoeller DA, Fukagawa NK, Wykes LJ \& Dietz W (1991) Body composition and energy expenditure in adolescents with cerebral palsy or myelodysplasia. Pediatric Research 29, 70-77.

Berke EM, Gardner AW, Goran MI \& Poehlman ET (1992) Resting metabolic rate and the influence of the pretesting environment. American Journal of Clinical Nutrition 55, 626-629.

Black AE, Coward WA, Cole TJ \& Prentice AM (1996) Human energy expenditure in affluent societies: an analysis of 574 doubly-labelled water measurements. European Journal of Clinical Nutrition 50, 72-92.

Bruder N, Lassegue D, Pelissier D, Graziani N \& Francois G (1994) Energy expenditure and withdrawal of sedation in severe headinjured patients. Critical Care Medicine 22, 1114-1119.

Carlsson M, Nordenstrom J \& Hedenstierna G (1984) Clinical implications of continuous measurement of energy expenditure in mechanically ventilated patients. Clinical Nutrition 3, 103-110.

Ceesay SM, Prentice AM, Day KC, Murgatroyd PR, Goldberg GR $\&$ Scott W (1989) The use of heart rate monitoring in the estimation of energy expenditure: a validation study using indirect whole-body calorimetry. British Journal of Nutrition 61, $175-186$.

Centers for Disease Control, Center for Infectious Diseases (1987) Acquired Immunodeficiency Syndrome Weekly Surveillance Report. US AIDS Program, 7 September issue. Washington, DC: Centers for Disease Control.

Coward WA (1988) Stable isotopic methods for measuring energy expenditure: the doubly labelled water $\left({ }^{2} \mathrm{H}_{2}{ }^{18} \mathrm{O}\right)$ method; principles and practice. Proceedings of the Nutrition Society 47, 209-218.

Cunningham JJ (1980) A reanalysis of the factors influencing basal metabolic rate in normal adults. American Journal of Clinical Nutrition 33, 2372-2374.

Cunningham JJ, Hegarty MT, Meara PA \& Burke JF (1989) Measured and predicted calorie requirements of adults during recovery from severe burn trauma. American Journal of Clinical Nutrition 49, 404-408.
Cuthbertson DP (1942) Post-shock metabolic response. Lancet i, 432-437.

Dauncey MJ \& James WPT (1979) Assessment of heart rate method for determining energy expenditure in man, using a whole body calorimeter. British Journal of Nutrition 42, 1-13.

Deitrick JE, Whedon GD, Shorr E, Toscani V \& Davis VB (1948) Effect of immobilization upon various metabolic and physiologic functions of normal men. American Journal of Medicine 4, 3-35.

Demark-Wahnefried W, Hars V, Conaway MR, Halvin K, Rimer BK, McElveen G \& Winer EP (1997) Reduced rate of metabolism and decreased physical activity in breast cancer patients receiving adjuvant chemotherapy. American Journal of Clinical Nutrition 65, 1495-1501.

Dempsey DT, Guenter P, Mullen JL, Fairman R, Crosby LO, Speilman G \& Gennarelli T (1985) Energy expenditure in acute trauma to the head with and without barbiturate therapy. Surgical Gynecological Obstetrics 160, 128-134.

Department of Health (1991) Dietary Reference Values for Food Energy and Nutrients for the United Kingdom. Report on Health and Social Subjects no. 41. London: H.M. Stationery Office.

Diffey B, Piers LS, Soares MJ \& O'Dea K (1997) The effect of oral contraceptive agents on the basal metabolic rate of young women. British Journal of Nutrition 77, 853-862.

Elia M (1991) The energy equivalents of carbon dioxide $\left(\mathrm{EeqCO}_{2}\right)$ and their importance in assessing energy expenditure with the use of tracer techniques. American Journal of Physiology 260, E75-E88.

Elia M (1995) Changing concepts of nutrient requirements in disease: implications for artificial nutritional support. Lancet 345, 1279-1284

Elia M, Jones MG, Jennings G, Poppitt SD, Fuller NJ, Murgatroyd PR \& Jebb SA (1995) Estimation of energy expenditure from specific activity of urine urea during lengthy subcutaneous $\mathrm{NaH}^{14} \mathrm{CO}_{3}$ infusion. American Journal of Physiology 269, E172-E182.

Freid RC, Dickerson RN, Guenter PA, Stein TP, Gennarelli TA, Dempsey DT, Buzby GP \& Mullen JL (1989) Barbiturate therapy reduces nitrogen excretion in acute head injury. Journal of Trauma 29, 1558-1564.

Garrow JS \& James WPT (editors) (1993) Human Nutrition and Dietetics, 9th ed. London: Churchill Livingstone.

Gibney E, Elia M, Jebb SA, Murgatroyd P \& Jennings G (1996) Total energy expenditure in patients with small cell lung cancer: Results of a validated study using the bicarbonate-urea method. Metabolism 46, 1412-1417.

Goran MI, Broemeling L, Herndon DN, Peters EJ \& Wolfe RR (1991) Estimating energy requirements in burned children: a new approach derived from measurements of resting energy expenditure. American Journal of Clinical Nutrition 54, 35-40.

Goran MI, Peters EJ, Herndon DN \& Wolfe RR (1985) Total energy expenditure in burned children using the doubly labelled water technique. American Journal of Physiology 259, E576-E585.

Goran MI, Poehlman ET \& Johnson RK (1994) Energy requirements across the lifespan: new findings based on measurement of total energy expenditure with doubly labelled water. Nutrition Research 15, 115-150.

Guzman FA, Plank LD, Monk DN, Gupta R, Maher K, Gillanders L \& Hill G (1994) A new method for the estimation of the components of energy expenditure in patients with major trauma. American Journal of Physiology 267, E1002-E1009.

Heijligenberg R, Romijn JA, Westerterp KR, Jonkers CF, Prins JM \& Sauerwein HP (1997) Total energy expenditure in Human Immunodeficiency Virus-Infected men and healthy control. Metabolism 46, 1324-1326.

Hellerstein MK, Kahn J, Mudie H \& Viteri F (1990) Current approach to the treatment of human immunodeficiency virus 
associated weight loss: pathophysiological considerations and emerging management strategies. Seminars in Oncology 17, $17-33$.

Jebb SA, Osborne RJ, Dixon AK, Bleehan NM \& Elia M (1994) Measurement of resting energy expenditure and body composition before and after treatment of small cell lung cancer Annals of Oncology 5, 915-919.

Klein PD, James WPT, Wong WW, Irving CS, Murgatroyd PR, Cabrera M, Dallasso HM, Klein ER \& Nichols BL (1984) Calorimetric validation of the doubly labelled water method for determination of energy expenditure in man. Human Nutrition Clinical Nutrition 38C, 95-106.

Koea JB, Wolfe RR \& Shaw JHF (1995) Total energy expenditure during total parenteral nutrition: ambulatory patients at home versus patients with sepsis in surgical intensive care. Surgery 118, 54-62.

Kushner RF \& Schoeller DA (1991) Resting and total energy expenditure in patients with inflammatory bowel disease. American Journal of Clinical Nutrition 53, 161-165.

Lifson N \& McClintock R (1966) Theory of use of the turnover rates of body water for measuring energy and material balance. Journal of Theoretical Biology 12, 46-74.

Long C (1979) Energy expenditure of major burns. Journal of Trauma 19, 904-906.

Long CL, Schaffel N, Geiger JW, Schiller WR \& Blakemore WS (1979) Metabolic responses to injury and illness: Estimation of energy and protein needs from indirect calorimetry and nitrogen balance. Journal of Parenteral and Enteral Nutrition 3 , 452-456.

McClave SA, Lowen CC, Kleber MJ, Nicholson JF, Jimmerson SC, McConnell JW \& Jung LY (1998) Are patients fed appropriately according to their caloric requirements? Journal of Parenteral and Enteral Nutrition 22, 375-381.

Mildreth M \& Carvajal HF (1982) Caloric requirements in burned children: A simple formula to estimate daily caloric requirements. Journal of Burn Care Rehabilitation 3, 78-80.

Mitchell IM, Davies PSW, Day JME, Pollock JCS, Jamieson MPG \& Wheatley DJ (1994) Energy expenditure in children with congenital heart disease, before and after cardiac surgery. Journal of Thoracic Cardiovascular Surgery 107, 374-380.

Molinger LA, Spurr GB, El Ghatit AZ, Barboriak JJ, Rooney CB, Davidoff DD \& Bongard RD (1985) Daily energy expenditure and basal metabolic rates of patients with spinal cord injury. Archives of Physical Medical Rehabilitation 66, 420-426.

Murgatroyd PR, Shetty PS \& Prentice AM (1993) Techniques for the measurement of human energy expenditure: a practical guide. International Journal of Obesity Related Metabolic Disorders 17, 549-568.

Nelson KA, Walsh D \& Sheehan FA (1994) The cancer anorexiacachexia syndrome. Journal of Clinical Oncology 12, 213-225.

Novick WM, Nusbaum N \& Stein TP (1988) The energy costs of surgery as measured by the doubly labelled water method. Surgery 103, 99-106.

Parkinson SA (1990) In vivo measurement of changes in body composition. PhD Thesis, University of Cambridge.

Paton NIJ, Elia M, Jebb SA, Jennings G, Macallan DC \& Griffin GE (1996) Total energy expenditure and physical activity measured with the bicarbonate urea method in patients with human immunodeficiency virus infection. Clinical Science 91, 241-245.

Pullicino EA (1991) Aspects of energy metabolism in hospitalised patients. PhD Thesis, University of Cambridge.

Pullicino E, Coward A \& Elia M (1993) Total energy expenditure in intravenously fed patients measured by the doubly labelled water technique. Metabolism 42, 58-64.
Ravussin E, Harper I, Rising R \& Bogardus C (1991) Energy expenditure by doubly labelled water: validation in lean and obese subjects. American Journal of Physiology 24, E402-E409.

Reed GW \& Hill JO (1996) Measuring the thermic effect of food. American Journal of Clinical Nutrition 63, 164-169.

Romon M, Edme J-L, Boulenguez C, Lescroat J-L \& Frimat P (1993) Circadian variation of diet-induced thermogenesis. American Journal of Clinical Nutrition 57, 476-480.

Royall D, Fairholm L, Peters WJ, Jeejeebhoy KN \& Allard JP (1994) Continuous measurement of energy expenditure in ventilated burn patients: an analysis. Critical Care Medicine 22, 399-406.

Schoeller DA, Ravussin E \& Schutz Y (1986) Energy expenditure by the doubly labelled water method: validation in humans. American Journal of Physiology 250, R823-R830.

Schoeller DA \& Webb P (1984) Five-day comparison of the doubly labelled water method with respiratory gas exchange. American Journal of Clinical Nutrition 40, 153-158.

Schofield WN, Schofield C \& James WPT (1985) Basal metabolic rate. Human Nutrition Clinical Nutrition 39, 1-96.

Schwenk A, Hoffer-Belitz E, Jung B, Kremer G, Burger B, Salzberger B, Diehl V \& Schrappe M (1996) Resting energy expenditure, weight loss, and altered body composition in HIV infection. Nutrition 12, 595-601.

Shepherd RW, Holt TL, Vasques-Velasquez L, Coward WA, Prentice A \& Lucas A (1988) Increased energy expenditure in young children with cystic fibrosis. Lancet i, 1300-1303.

Soares MJ \& Shetty PS (1986) Intra individual variations in resting metabolic rates of human subjects. Human Nutrition Clinical Nutrition 40C, 365-369.

Spurr GB, Prentice AM, Murgatroyd PR, Goldberg GR, Reina JC \& Christman BS (1988) Energy expenditure from minute-minute heart rate recording: comparison with indirect calorimetry. American Journal of Clinical Nutrition 48, 552-559.

Stallings VA, Zemel BS, Davies JC, Cronk CE \& Charney EB (1996) Energy expenditure of children and adolescents with severe disabilities: a cerebral palsy model. American Journal of Clinical Nutrition 64, 627-634.

Taggart DP, McMillan DC, Preston C, Richardson R, Burns RJG \& Wheatley DJ (1991) Effects of cardiac surgery and intraoperative hypothermia on energy expenditure as measured by the doubly labelled water. British Journal of Surgery 78, 237-241.

Tomesko JL, Stallings VA, Kawchak DA, Goin JE, Diamond G \& Scanlin TF (1994) Energy expenditure and genotype of children with cystic fibrosis. Pediatric Research 35, 451-460.

Turner WW, Ireton CS, Hunt JL \& Baxter CR (1985) Predicting energy expenditures in burned patients. Journal of Trauma $\mathbf{2 5}$, $11-16$.

Weekes E \& Elia M (1996) Observations on the patterns of $24 \mathrm{~h}$ energy expenditure and changes in body composition and gastric emptying in head injured patients. Journal of Parenteral and Enteral Nutrition 20, 31-37.

Weissman C, Kemper M, Elwyn DH, Asksanazi J, Hyman AI \& Kinney JM (1986) The energy expenditure of the mechanically ventilated critically ill patient. Chest $\mathbf{8 9}, 254-259$.

Westerterp KR, Brouns F, Saris WHM \& Tenhoor F (1988) Comparison of doubly labelled water with respirometry at low and high activity levels. American Journal of Physiology 65, $53-56$.

Wolfe RR (1982) Caloric requirements of the burned patient. Journal of Trauma 21, 712-714.

Young B, Ott L, Norton J, Tibbs P, Rapp R, McClain C \& Dempsey $\mathrm{R}$ (1985) Metabolic and nutritional sequelae in the non-steroid treated head injured patient. Neurosurgery 17, 784-791. 